\title{
Embryogenesis in Vitro and Nonchimeric Tetraploid Plant Recovery from Undeveloped Citrus Ovules Treated with Colchicine
}

\author{
Frederick G. Gmitter, Jr., and Xubai Ling ${ }^{2}$ \\ Citrus Research and Education Center, University of Florida, IFAS, 700 Experiment Station Road, \\ Lake Alfred, FL 33850
}

Additional index words. in vitro regeneration, fruit breeding, interploid hybridization, sweet orange, tangelo, seedlessness

\begin{abstract}
A method was developed to produce nonchimeric, autotetraploid Citrus plants via in vitro somatic embryogenesis in the presence of colchicine. Undeveloped ovules from immature fruit of 'Valencia' sweet orange (Citrus sinensis [L.] Osb.) and 'Orlando' and 'Minneola' tangelos (Citrus reticulata Blanco $\times$ Citrus $\times$ paradisi Macf.) were held on Murashige and Tucker medium with $500 \mathrm{mg}$ malt extract/liter and $0.0090,0.01 \%$, or $0.10 \%$ colchicine for 21 days. Embryogenesis from tangelo ovules was suppressed by $0.10 \%$ colchicine, but no such effect was observed among sweet orange ovules. Colchicine treatments had no subsequent effect on embryo germination. The numbers of chromosomes in root tip cells showed that both tetraploid and diploid 'Valencia' and 'Orlando' plants were recovered from colchicine treatments. 'Minneola' cultures produced only diploid plants. Tetraploid plant morphology was typical for Citrus tetraploids. Examination of chromosome numbers in root tip, shoot, and leaf meristems indicated that the regenerants were nonchimeric. Such nonchimeric tetraploids will be useful parents for interploid hybridization directed toward development of seedless triploid Citrus scion cultivars.
\end{abstract}

Heedlessness is an important characteristic for consumer acceptance of citrus fruit for fresh consumption. Most of the commercially important cultivars of sweet orange (C. sinensis), grapefruit $(C . \times$ paradisi $)$, mandarin $(C$. reticulata), and lemon (C. limon [L.] Burro.) are seedless; thus, this characteristic is considered an essential breeding objective for Citrus scion cultivar development programs (Soost and Cameron, 1975). Citrus triploids such as 'Tahiti' lime (C. aurantifolia [Christm.] Swing.) or 'Oroblanco' and 'Melogold' hybrids (diploid C. grandis [L.] Osb. $\times$ tetraploid C. $\times$ paradisi) are seedless (Krug and Bacchi, 1943; Soost and Cameron, 1969, 1980, 1985). The triploid procimequat, a hybrid of tetraploid Fortunella hindsii (Champ.) Swing. with a diploid hybrid of Fortunella japonica (Thunb.) Swing. $\times C$. aurantifolia, produces seeds and is an exception (Swingle and Reece, 1967). Citrus tissue cultures have yielded triploid callus lines (Zhang, 1985), and triploid Citrus hybrid plants have been recovered from in vitro endosperm cultures (Gmitter et al., 1991). However, Citrus triploids have been produced most frequently by interploid hybridization, usually using tetraploids as seed parents (Lee, 1988).

There are too few available tetraploid Citrus selections representing too small a fraction of the gene pool to exploit fully the potential to produce seedless cultivars by interploid hybridization (Barrett, 1974). Tetraploid Citrus plants have arisen: 1) as spontaneous nucellar seedlings (Barrett and Hutchison, 1978), 2) by colchicine treatment of axillary meristems (Barrett, 1974), 3) following $2 x \times 4 x$ hybridization (Cameron and Soost, 1969), 4) as spontaneous tissue culture-derived variants (Vardi, 1981;

\footnotetext{
Received for publication 26 Apr. 1990. Florida Agricultural Experiment Station Journal Series no. R-00692. We gratefully acknowledge the technical assistance of C. Cai, D. Chen, X. Deng, S. Huang, and M.K. Wendell; T. Zito for photography; and P. Hicks for manuscript preparation. This work was supported in part by a grant from the U.S. Dept. of Agriculture (86-CRCR-1-2002). The cost of publishing this paper was defrayed in part by the payment of page charges. Under postal regulations, this paper therefore must be hereby marked advertisement solely to indicate this fact.

${ }^{1}$ Assistant Professor

${ }^{2}$ Visiting Scientist. Current address: South China College of Tropical Crops, Danxin County, Hainan, PRC
}

Zhang, 1985), and 5) by somatic hybridization (Grosser and Gmitter, 1990; Kobayashi and Ohgawara, 1988). There are limitations associated with most of the methods of tetraploid induction. For example, it may be necessary to grow hundreds or thousands of nucellar seedlings or tissue culture regenerants to find spontaneous tetraploids of desired clones. Colchiploids arising from meristem treatment may be cytochimeras and, therefore, of limited utility for breeding (Barrett, 1974). A reliable method to create nonchimeric, autotetraploid plants from superior diploid selections would be useful to increase the number of breeding parents available for triploid Citrus scion breeding.

Tissue culture techniques have been used to regenerate plants with doubled chromosome numbers. Shoot cultures of diploid Vaccinium elliotii Chap. and tetraploid V. corymbosum L. yielded tetraploid and octoploid plants, respectively, following colchicine treatment and axillary bud proliferation in vitro, although some of the recovered polyploids were chimeras (Goldy and Lyrene, 1984; Lyrene and Perry, 1982). Gupton (1989) recovered tetraploid plants from two diploid Rubus species following in vitro shoot proliferation with colchicine. He concluded that the tetraploids were nonchimeric, based on root tip chromosome number, pollen size, and stomatal characteristics. James et al. (1987) used colchicine with an adventitious bud regeneration technique in vitro to recover five hexaploid plants from root-derived calli of triploid Colt cherry (Prunus pseudocerasus $\times P$. avium); at least one of the recovered hexaploids was chimeric.

We wished to determine the feasibility of recovering nonchimeric tetraploid Citrus plants following in vitro somatic embryogenesis from undeveloped ovules on medium containing colchicine. Somatic embryogenesis in vitro from nucellar tissue in undeveloped and presumably unfertilized Citrus ovules is well-documented (Button and Bornman, 1971; Moore, 1985; Starrantino and Russo, 1980). Nucellar embryo development proceeds from adventive embryo initial cells that originate before anthesis (Wakana and Uemoto, 1988) and extends to the globular stage found in undeveloped ovules in mature fruit (Starrantino and Russo, 1980). Our objectives were to determine the effect of colchicine treatment on in vitro embryogenesis and 
Table 1. Frequency of somatic embryogenesis from undeveloped Citrus ovules in vitro 3 and 6 months after exposure to colchicine.

\begin{tabular}{|c|c|c|c|c|c|c|c|}
\hline \multirow[b]{3}{*}{ Cultivar } & \multirow{3}{*}{$\begin{array}{c}\text { Time } \\
\text { after } \\
\text { treatment } \\
\text { (months) }\end{array}$} & \multicolumn{6}{|c|}{ Colchicine concn } \\
\hline & & \multicolumn{2}{|c|}{$0.00 \%$} & \multicolumn{2}{|c|}{$0.01 \%$} & \multicolumn{2}{|c|}{$0.10 \%$} \\
\hline & & No. ${ }^{7}$ & $\%$ & No. & $\%$ & No. & $\%$ \\
\hline \multirow[t]{2}{*}{ Valencia } & 3 & $32 /$ & 26 & $17 /$ & 14. & $1 / 120$ & 25.8 \\
\hline & 6 & 52 & 4 & 44 & 36.7 & $58 / 120$ & 48.3 \\
\hline \multirow[t]{2}{*}{ Orlando } & 3 & $31 / 100$ & 31.0 & $40 / 100$ & 40.0 & $5 / 80$ & 6 \\
\hline & 6 & $53 / 100$ & 53.0 & $52 / 100$ & 52.0 & $25 / 80$ & 31.3 \\
\hline \multirow[t]{2}{*}{ Minneola } & 3 & $26 / 120$ & 21.6 & $37 / 120$ & 30.8 & $2 / 60$ & 3.3 \\
\hline & 6 & $57 / 120$ & 47.5 & $71 / 120$ & 59.2 & $6 / 60$ & 10.0 \\
\hline
\end{tabular}

${ }^{2}$ Number of embryogenic ovules per number of ovules cultured. Treatments with $<120$ ovules indicate contamination losses.

plant regeneration from undeveloped Citrus ovules and to recover any resulting nonchimeric tetraploid plants.

\section{Materials and Methods}

Immature fruit from open-pollinated flowers were harvested 12 to 14 weeks post-anthesis from trees of 'Valencia' sweet orange, and 'Orlando' and 'Minneola' tangelos. Undeveloped ovules were excised and surface-sterilized using standard methods (Moore, 1985). Murashige and Tucker (1969) basal medium (MT) for Citrus was prepared with $500 \mathrm{mg}$ malt extract/liter (EME) and $0.00 \%, 0.01 \%$, or $0.10 \%$ colchicine (w/v) added before autoclaving at $1.1 \mathrm{~kg} \cdot \mathrm{cm}^{-2}$ for $20 \mathrm{~min}$. Twenty undeveloped ovules were placed on medium in each of six petri dishes $(100 \times 20 \mathrm{~mm})$ per treatment for each cultivar. Ovules and consequent proliferation were transferred to fresh medium without colchicine 3 weeks post-inoculation and every 8 weeks subsequently. The maximum exposure time to colchicine was 21 days. The total percentage of ovules producing embryos and/ or embryogenic callus was determined 3 and 6 months after treatment. Cotyledonary embryos were harvested 5 to 6 months after treatment and placed on MT medium with gibberellic acid ( $5 \mathrm{mg} \cdot$ liter $^{-1}$ ) to induce germination. Germinated embryos with roots and shoots were planted in a standard artificial soil mix and kept in high humidity to acclimate before transfer to a glasshouse.

Chromosomes were counted in various somatic tissues to determine the ploidy level of regenerants from colchicine treatments. Root tips were collected from 10 to 15 germinated embryos randomly selected from each cultivar and treatment 8 to 10 weeks after transfer to germination medium. Chromosomes were counted also in preparations of root tips, axillary meristems, and newly emerging leaves of selected diploid and tetraploid plants, from the glasshouse, that had been classified according to differences in vegetative morphology and by root tip chromosome numbers. Modifications of a ferric ammonium sulfatehematoxylin stain procedure were used to stain chromosomes (Gmitter et al., 1991).

\section{Results}

Incorporation of $0.01 \%$ colchicine in the medium had little suppressive effect on embryogenesis from undeveloped ovules after 3 months (Table 1). The high colchicine concentration $(0.10 \%)$ suppressed embryogenesis from 'Orlando' and 'Minneola' tangelo ovules during the first 3 months, but it had no effect on 'Valencia' sweet orange ovules. Suppression of embryogenesis from tangelo ovules continued 6 months after $0.10 \%$ colchicine "treatment, although 'Orlando' cultures recovered somewhat; in contrast, embryogenesis from 'Valencia' sweet orange ovule cultures was not affected. Although effects of colchicine on the frequency of embryogenesis were minimal, embryos that arose on colchicine-amended media more frequently exhibited malformed cotyledons and other morphological abnormalities than those from the control. However, the germination frequency of cotyledonary embryos showed no clear relationship to initial colchicine treatment, despite morphological aberrations (Table 2).

Diploid and tetraploid 'Valencia' and 'Orlando' plantlets were recovered from both colchicine treatments according to chromosome counts of root tip cells (Figs. 1 and 2); however, tetraploid 'Minneola' plantlets were not recovered from any of the treatments (Table 3). Only diploid plants were recovered from control groups. Chromosome numbers observed in shoot or leaf meristem cells of plants, identified as diploid or tetraploid by examination of root tip preparations, provided evidence that regenerated plants were not cytochimeras. Only diploid cells were found in diploid plants, and plants identified as tetraploid had only tetraploid cells in axillary bud preparations (Table 4). The data in Table 4 included counts only from undamaged cells for which clear, precise determinations of chromosome numbers could be made. Many more cells were observed from each plant with $<18$ or $<36$ chromosomes from diploids or tetraploids, respectively; in most of these cells, chromosomes were not sufficiently separated for accurate counts. However, in no case were diploid cells found in tetraploid plants, or vice versa.

Plantlets of all cultivars were transferred to soil, and all successfully acclimated to glasshouse conditions. Gross vegetative morphology of 'Valencia' and 'Orlando' tetraploids was different from respective diploids. Stems of tetraploids were more stout than diploids and their leaves were characteristically thicker,

Table 2. Citrus embryo germination on MT medium with gibberellic acid $\left(5 \mathrm{mg} \cdot \mathrm{liter}^{-1}\right)$. The number of embryos with shoots and roots was recorded 6 weeks after transfer.

\begin{tabular}{|c|c|c|c|c|c|c|}
\hline \multirow[b]{3}{*}{ Cultivar } & \multicolumn{6}{|c|}{ Original colchicine concn } \\
\hline & \multicolumn{2}{|c|}{$0.00 \%$} & \multicolumn{2}{|c|}{$0.01 \%$} & \multicolumn{2}{|c|}{$0.10 \%$} \\
\hline & No. ${ }^{2}$ & $\%$ & No. & $\%$ & No. & $\%$ \\
\hline Valencia & $52 / 66$ & 78.8 & $92 / 152$ & 60.5 & $42 / 68$ & 61.8 \\
\hline Orlando & $53 / 84$ & 63.1 & $73 / 85$ & 85.9 & $24 / 36$ & 66.7 \\
\hline Minneola & $46 / 48$ & 95.8 & $70 / 89$ & 78.7 & $1 / 1^{y}$ & 100 \\
\hline
\end{tabular}

${ }^{2}$ Number of germinated embryos per number of embryos transferred. 'Embryo production from 'Minneola' ovules on $0.10 \%$ colchicine medium was low because only six ovules responded. 


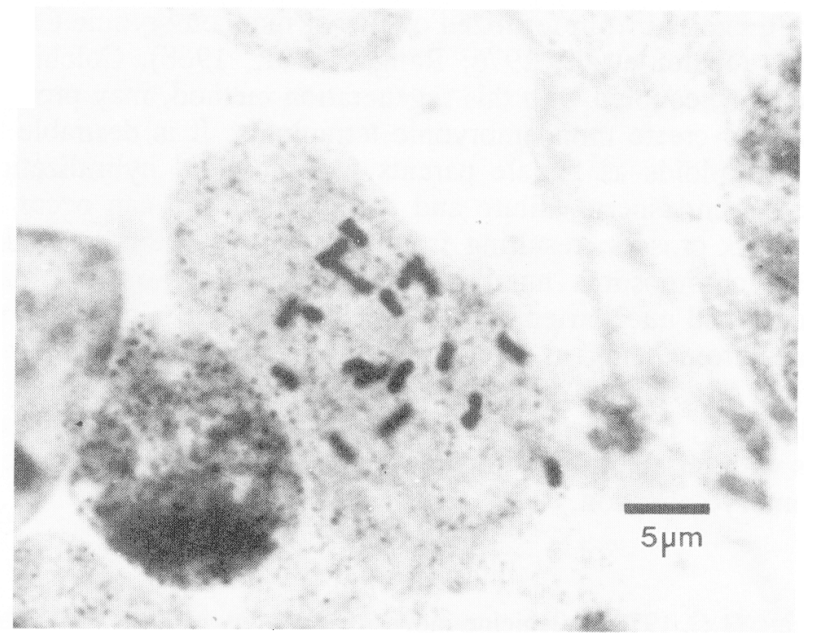

'Fig. 1. Root tip cell from 'Valencia' sweet orange plant regenerated following in vitro treatment of undeveloped ovules with colchicine $(0.10 \%), 2 n=2 x=18$.

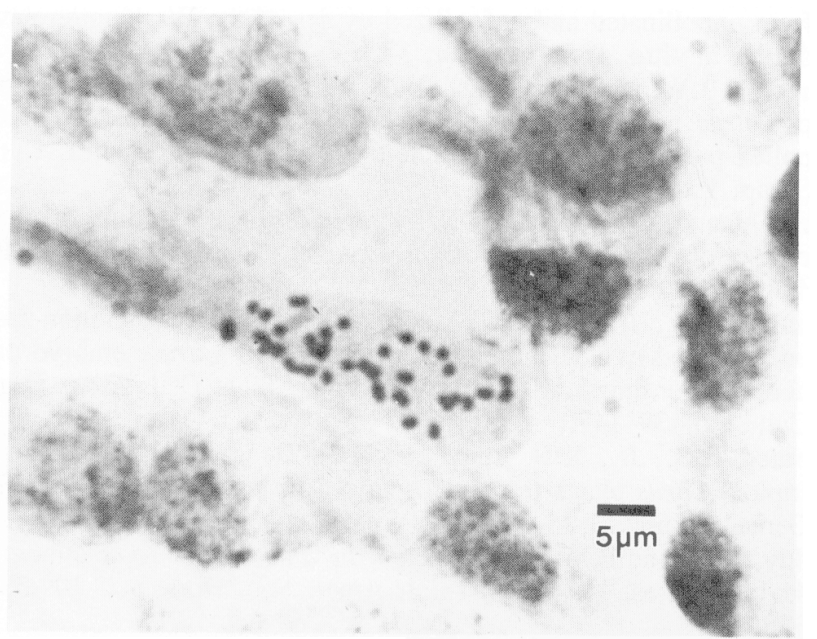

Fig. 2. Root tip cell from 'Orlando' tangelo plant regenerated following in vitro treatment of undeveloped ovules with colchicine $(0.10 \%), 2 \mathrm{n}=4 \mathrm{x}=36$.

Table 3. Number of diploid and tetraploid plantlets derived from in vitro colchicine treatment of undeveloped Citrus ovules. From 10 to 15 germinated embryos were randomly selected from each cultivar and treatment group for ploidy determination, except as noted in text for "Minneola."

\begin{tabular}{lllll} 
& \multicolumn{4}{c}{ Original colchicine concn } \\
\cline { 2 - 4 } \cline { 5 - 6 } Cultivar & $2 \mathrm{x}$ & $4 \mathrm{x}$ & & \multicolumn{2}{c}{$0.10 \%$} \\
\hline Valencia & 10 & 3 & 12 & $4 \mathrm{x}$ \\
Orlando & 10 & 2 & 4 & 3 \\
Minneola & 10 & 0 & $\ldots$ & 7 \\
\hline
\end{tabular}

wider, rounder, and darker green (Figs. 3 and 4). 'Valencia' orange tetraploids were less vigorous than diploids, but 'Orlando' tangelo tetraploids were of equal or greater vigor than diploids.

\section{Discussion}

We have demonstrated that in vitro somatic embryogenesis from undeveloped ovules, in the presence of colchicine, can be
Table 4. Chromosome numbers in root tip, shoot, and leaf meristem cells of selected diploid and tetraploid 'Orlando' tangelo plants that arose from in vitro treatment of undeveloped ovules with colchicine $(0.10 \%)$.

\begin{tabular}{|c|c|c|c|}
\hline & \multirow[b]{2}{*}{ Tissue } & \multicolumn{2}{|c|}{ No. cells with: } \\
\hline & & $2 n=18$ & $2 n=36$ \\
\hline \multicolumn{4}{|c|}{ 2x Plants } \\
\hline A & Root tip & 13 & 0 \\
\hline$A$ & Shoot/leaf meristems & 6 & 0 \\
\hline $\mathrm{B}$ & Root tip & 7 & 0 \\
\hline $\mathrm{B}$ & Shoot/leaf meristems & 7 & 0 \\
\hline $\mathrm{C}$ & Shoot/leaf meristems & 5 & 0 \\
\hline $\mathrm{D}$ & Shoot/leaf meristems & 5 & 0 \\
\hline \multicolumn{4}{|c|}{$4 \mathrm{x}$ Plants } \\
\hline A & Root tip & 0 & 5 \\
\hline B & Root tip & 0 & 14 \\
\hline C & Shoot/leaf meristems & 0 & 20 \\
\hline D & Shoot/leaf meristems & -0 & 20 \\
\hline $\mathrm{E}$ & Shoot/leaf meristems & 0 & 27 \\
\hline $\mathrm{F}$ & Shoot/leaf meristems & 0 & 7 \\
\hline G & Shoot/leaf meristems & 0 & 6 \\
\hline $\mathrm{H}$ & Shoot/leaf meristems & 0 & 7 \\
\hline
\end{tabular}

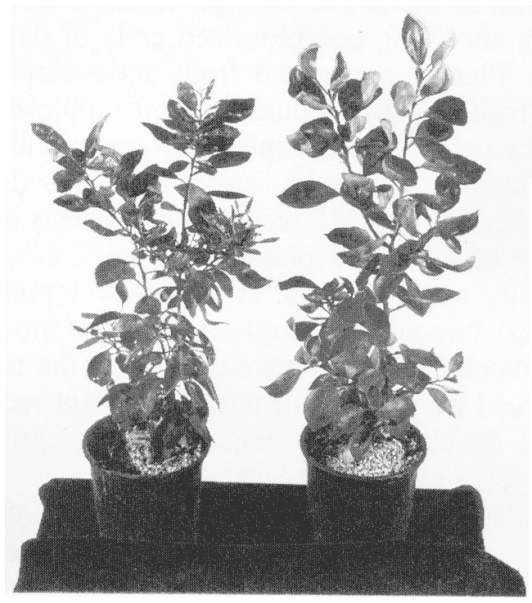

Fig. 3. Diploid (left) and tetraploid (right) 'Orlando' tangelo plants regenerated following in vitro treatment of undeveloped ovules with colchicine $(0.10 \%)$.

used to create nonchimeric tetraploid plants from desirable polyembryonic Citrus selections; such tetraploids will be valuable breeding parents, if adequately fertile, for interploid hybridizations directed toward seedless triploid Citrus scion cultivars. Treatment of undeveloped Citrus ovules with colchicine during initiation of somatic embryogenesis in vitro had little or no effect on the efficiency of plant regeneration, depending on cultivar. Response frequencies were similar to those reported from undeveloped ovules of mature fruit (Gmitter and Moore, 1986). Differential sensitivity to the $0.10 \%$ colchicine treatment was observed among cultivars; for example, this treatment reduced the frequency of embryogenesis from 'Minneola' ovules. However, this concentration can be recommended to increase the frequency of polyploidization and thus tetraploid plant recovery.

The evidence provided by examination of chromosome numbers in shoot and leaf meristem cells indicated that recovered plants were not cytochimeras and, therefore, were of single-cell origin. The stage of nucellar embryo development in undevel- 


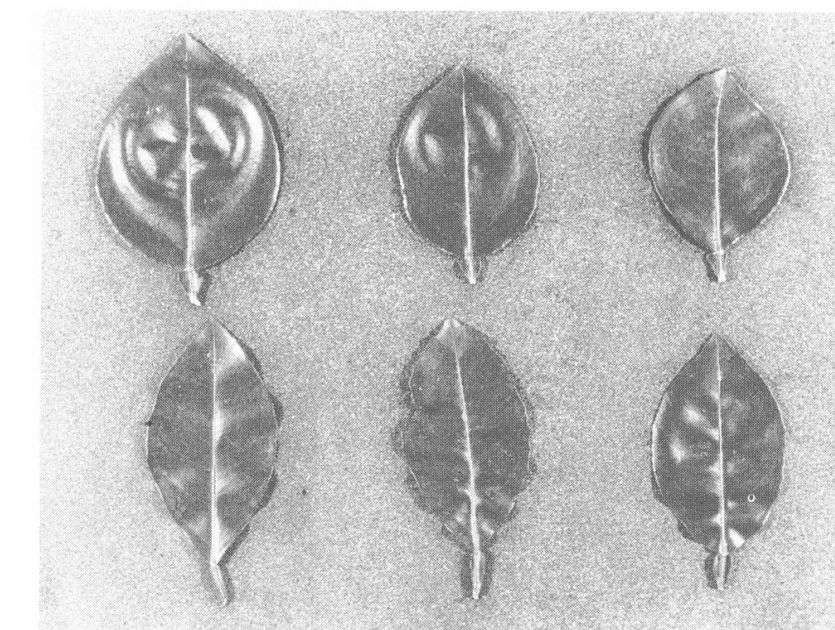

Fig. 4. Tetraploid (above) and diploid (below) 'Valencia' sweet orange leaves from plants regenerated following in vitro treatment of undeveloped ovules with colchicine $(0.10 \%)$.

oped ovules at the time of inoculation was not determined. The embryos that became tetraploid plants must have developed either from polyploidized adventive embryo initial cells (unicellular) or from single surviving polyploidized cells of damaged globular embryos. Plants regenerated from undeveloped ovules of more mature fruit possibly would be either diploid (unaffected embryos) or cytochimeric mixoploids because embryos at that stage are multicellular. Likewise, using undeveloped ovules from fruit harvested earlier than 12 weeks post-anthesis may increase the percentage of tetraploid plants recovered, despite possible greater mortality rates, because embryo development may not have proceeded beyond the single-cell stage. Studies relating the stage of nucellar embryo development at the time of treatment to observed frequencies of tetraploid plant recovery could determine the developmental stage most susceptible to polyploidization, yet capable of regeneration.

Barrett (1974) identified cytochimeric mixoploids, following in vivo treatment of axillary buds with colchicine, by microscopic examination of sectioned apical meristems; determination of the ploidy level of specific histogenic layers was based primarily on size differences of cells and interphase nuclei. This procedure was not used with our regenerated plants, but it is reasonable to expect that cells with different chromosome numbers would have been observed within individual meristems or plants if the regenerants were cytochimeras. In fact, we never observed mixoploidy in any diploid or tetraploid regenerant.

Tetraploid plants of each cultivar were morphologically uniform and exhibited characteristics typical of other described tetraploid Citrus (Soost and Cameron, 1975). 'Valencia' tetraploids grew more slowly than diploids and produced less upright and more horizontally oriented shoot growth. In contrast, 'Orlando' tetraploids were of equal or greater vigor than diploids. This vigor may be related to the interspecific hybrid origin of 'Orlando'. Some autotetraploid clones of grapefruit [considered to be an interspecific hybrid (Scora et al., 1982)] have proven also to be vigorous (Soost and Cameron, 1975). Heterozygosity in these diploid hybrids maybe greater than in sweet orange, and their derived autotetraploids may be better able to tolerate the deleterious effects of polyploidy on plant growth.

No monoembryonic clones were included in this study. Although their undeveloped ovules rarely undergo somatic embryogenesis (Moore, 1985), embryogenesis has been induced in nucelli excised from fertilized ovules of monoembryonic Citrus clones (Juarez et al., 1976; Rangan et al., 1968). Colchicine treatment, coupled with this regeneration method, may provide a way to create monoembryonic tetraploids. It is desirable to use tetraploids as female parents for interploid hybridization because endosperm failure and embryo abortion can occur in $2 \mathrm{x} \times 4 \mathrm{x}$ crosses, resulting from unfavorable embryo : endosperm chromosome number ratios (Esen and Soost, 1972). Widespread nucellar embryony precludes most desirable Citrus clones from being used effectively as seed parents, whether diploid or tetraploid. Rescue of triploid embryos, using in vitro techniques, from crosses of diploid monoembryonic seed parents with tetraploid pollen parents may circumvent the problem of embryo abortion.

\section{Literature Cited}

Barrett, H.C. 1974. Colchicine-induced polyploidy in citrus. Bot. Gaz. 135:29-41.

Barrett, H.C. and D.J. Hutchison. 1978. Spontaneous tetraploidy in apomictic seedlings of Citrus. Econ. Bot. 32:27-45.

Button, J. and C.H. Bornman. 1971. Development of nucellar plants from unpollinated and unfertilized ovules of the Washington navel orange in vitro. J. S. Afr. Bot. 37:127-134.

Cameron, J.W. and R.K. Soost. 1969. Characters of new populations of Citrus polyploids, and the relation between tetraploidy in the pollen parent and hybrid tetraploid progeny. Proc. 1st Intl. Citrus Symp, 1:199-205.

Esen, A. and R.K. Soost. 1972. Tetraploid progenies from $2 \mathrm{x} \times 4 \mathrm{x}$ crosses of Citrus and their origin. J. Amer. Soc. Hort. Sci. 97:410414

Gmitter, F.G., Jr. and G.A. Moore. 1986. Plant regeneration from undeveloped ovules and embryogenic calli of Citrus: embryo production, germination, and plant survival. Plant Cell Tissue Organ Culture 6:139-147.

Gmitter, F.G., Jr., X.B. Ling, and X.X. Deng. 1991. Induction of triploid Citrus plants from endosperm calli in vitro. Theor. Applied Genet. (In press.)

Goldy, R.G. and P.M. Lyrene. 1984. In vitro colchicine treatment of $4 \times$ blueberries, Vaccinium sp. J. Amer. Soc. Hort. Sci. 109:336338 .

Grosser, J.W. and F.G. Gmitter, Jr. 1990. Somatic hybridization of Citrus with wild relatives for germplasm enhancement and cultivar development. HortScience 25:147-151.

Gupton, C.L. 1989. Production of non-chimeral colchiploids in Rubus species by tissue culture. Euphytica 44:133-135.

James, D.J., K.A.D. Mackenzie, and S.B. Malhotra. 1987. The induction of hexaploidy in cherry rootstock using in vitro regeneration techniques. Theor. Applied Genet. 73:589-594.

Juarez, J., L. Navarro, and J.L. Guardiola. 1976. Obtention de plantes nucellaires de divers cultivars de clementiniers au moyen de la culture de nucelle in vitro. Fruits 31:751-762.

Kobayashi, S. and T. Ohgawara. 1988. Production of somatic hybrid plants through protoplasm fusion in citrus. JARQ 22:181-188.

Krug, C.A. and O. Bacchi. 1943. Triploid varieties of Citrus. J. Hered. 34:277-283.

Lee, L.S. 1988. Citrus polyploidy-origins and potential for cultivar improvement. Austral. J. Agr. Res. 39:735-747.

Lyrene, P.M. and J.L. Perry. 1982. Production and selection of blueberry polyploids in vitro. J. Hered. 73:377-378.

Moore, G.A. 1985. Factors affecting in vitro embryogenesis from undeveloped ovules of mature Citrus fruit. J. Amer. Soc. Hort. Sci. 110:66-70.

Murashige, T. and D.P.H. Tucker. 1969. Growth factor requirements of citrus tissue culture. Proc. 1st Intl. Citrus Symp. 3:1155-1161.

Rangan, T.S., T. Murashige, and W.P. Bitters. 1968. In vitro initiation of nucellar embryos in monoembryonic Citrus. HortScience 3:226227. 
Scora, R.W., J. Kumamoto, R.K. Soost, and E.M. Nauer. 1982. Contribution to the origin of the grapefruit, Citrus paradisi (Rutaceae). Syst. Bot. 7:170-177.

Soost, R.K. and J.W. Cameron. 1969. Tree and fruit characters of Citrus triploids from tetraploid by diploid crosses. Hilgardia 39:569579.

Soost, R.K. and J.W. Cameron. 1975. Citrus, p. 507-540. In: J. Janick and J.N. Moore (eds.). Advances in fruit breeding. Purdue Univ. Press, West Lafayette, Ind.

Soost, R.K. and J.W. Cameron. 1980. 'Oroblanco', a triploid pummelo-grapefruit hybrid. HortScience 15:667-669.

Soost, R.K. and J.W. Cameron. 1985. 'Melogold', a triploid pummelo-grapefruit hybrid. HortScience 20:1134-1135.

Starrantino, A. and F. Russo. 1980. Seedlings from undeveloped ovules of ripe fruits of polyembryonic citrus cultivars. HortScience 15:296297.

Swingle, W.T. and P.C. Reece. 1967. The botany of citrus and its wild relatives, p, 190-430. In: W. Reuther, L.D. Batchelor, and H.J. Webber (eds.). The citrus industry, vol. I. Univ. of California Press, Berkeley.

Vardi, A. 1981. Protoplasm derived plants from different Citrus species and cultivars. Proc. Intl. Soc. Citriculture 1:149-152.

Wakana, A. and S. Uemoto. 1988. Adventive embryogenesis in citrus (Rutaceae). II. Postfertilization development. Amer. J. Bot. 75:10331047.

Zhang, W. 1985. Citrus clonal selection, progeny testing and in vitro propagation. Fruit Var. J. 39:20-33. 